This document was prepared in conjunction with work accomplished under Contract No. DE-AC09-96SR18500 with the U. S. Department of Energy.

\title{
DISCLAIMER
}

This report was prepared as an account of work sponsored by an agency of the United States Government. Neither the United States Government nor any agency thereof, nor any of their employees, nor any of their contractors, subcontractors or their employees, makes any warranty, express or implied, or assumes any legal liability or responsibility for the accuracy, completeness, or any third party's use or the results of such use of any information, apparatus, product, or process disclosed, or represents that its use would not infringe privately owned rights. Reference herein to any specific commercial product, process, or service by trade name, trademark, manufacturer, or otherwise, does not necessarily constitute or imply its endorsement, recommendation, or favoring by the United States Government or any agency thereof or its contractors or subcontractors. The views and opinions of authors expressed herein do not necessarily state or reflect those of the United States Government or any agency thereof. 


\section{Uranium Metal to Oxide Conversion by Air Oxidation -Process Development}

Savannah River National Laboratory

Washington Savannah River Company

Publication Date: December, 2005

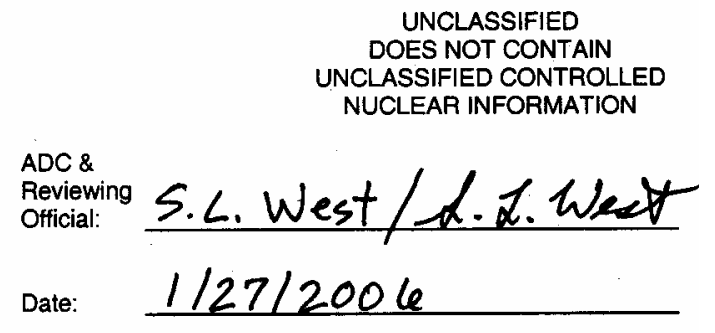

\section{Washington Savannah River Company Savannah River Site Aiken, SC 29808}

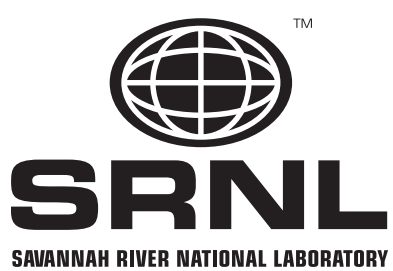

This document was prepared in connection with work done under Contract No. DE-AC09-96SR18500 with the U. S. Department of Energy 


\section{DISCLAIMER}

This report was prepared as an account of work sponsored by an agency of the United States Government. Neither the United States Government nor any agency thereof, nor any of their employees, makes any warranty, express or implied, or assumes any legal liability or responsibility for the accuracy, completeness, or usefulness of any information, apparatus, product, or process disclosed, or represents that its use would not infringe privately owned rights. Reference herein to any specific commercial product, process, or service by trade name, trademark, manufacturer, or otherwise does not necessarily constitute or imply its endorsement, recommendation, or favoring by the United States Government or any agency thereof. The views and opinions of authors expressed herein do not necessarily state or reflect those of the United States Government or any agency thereof. 
DOCUMENT: WSRC-TR-2005-00440 Rev. 0

TITLE: Uranium Metal to Oxide Conversion by Air Oxidation -Process Development

\section{APPROVALS}

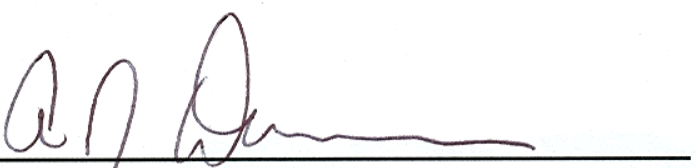

A.J. Duncan, Author SRNL-MATERIALS SCIENCE \& TECHNOLOGY Materials Applications \& Process Technology Group

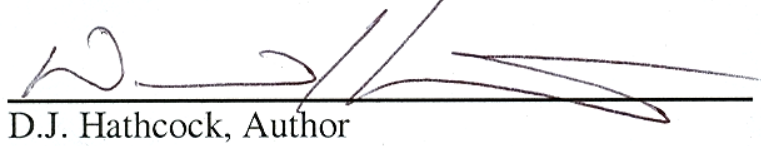

SRNL-MATERIALS SCIENCE \& TECHNOLOGY

Materials Applications \& Process Technology Group

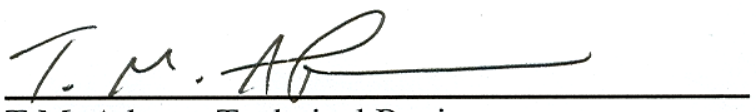

T.M. Adams, Technical Review

SRNL-MATERIALS SCIENCE \& TECHNOLOGY

Materials Applications \& Process Technology Group

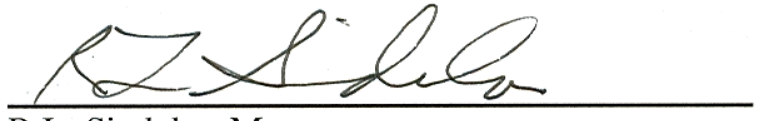

R.L. Sindelar, Manager

SRNL-MATERIALS SCIENCE \& TECHNOLOGY

Materials Applications \& Process Technology Group

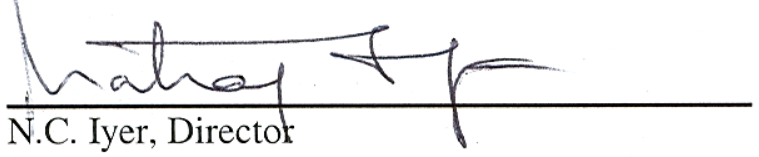

SRNL-MATERIALS SCIENCE \& TECHNOLOGY
Date: $12 / 21 / 25$

Date: $12 / 2 / 105^{-}$

Date: $12 / 31 / 05$

Date: $12 / 21 / 05$

Date: $1 / 24 / 06$ 


\section{Table of Contents}

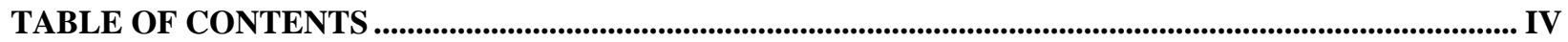

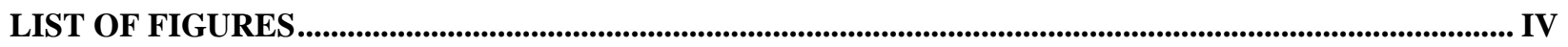

EXECUTIVE SUMMARY ...................................................................................................................................................

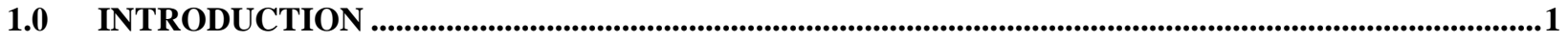

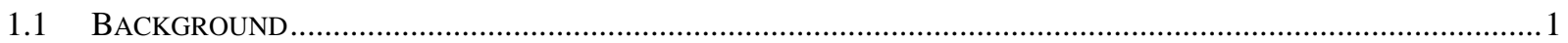

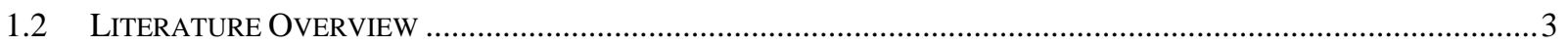

1.2.1 Low Temperature Oxidation: (i.e.100-300 $\left.{ }^{\circ} \mathrm{C}\right)$....................................................................................

1.2.2 Intermediate Temperature Oxidation: (i.e.300-650 ${ }^{\circ}$ C).......................................................................6

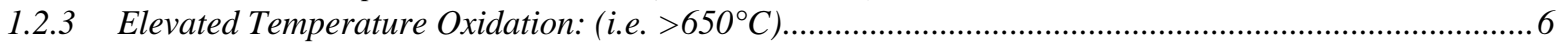

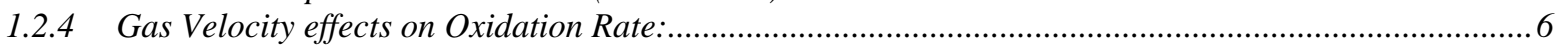

2.0 GENERAL PERFORMANCE REQUIREMENTS FOR SYSTEM ......................................................9

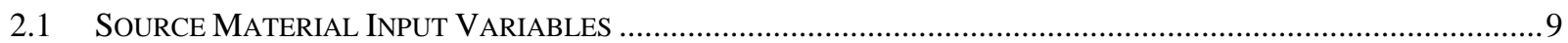

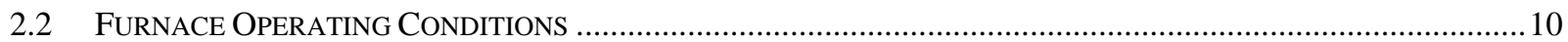

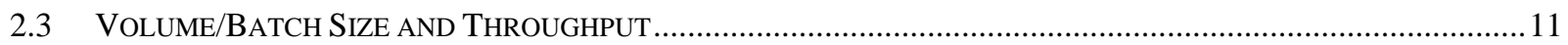

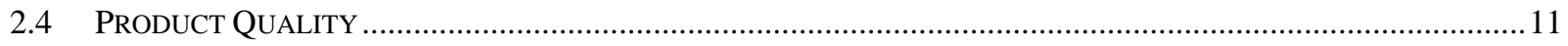

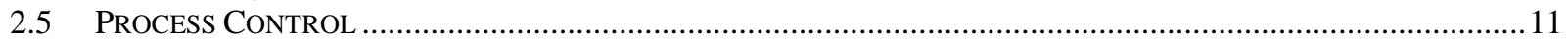

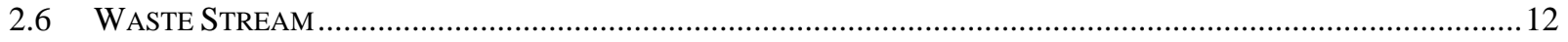

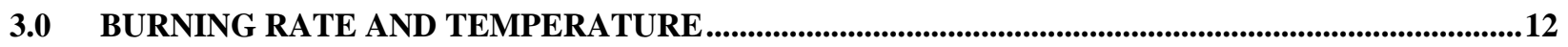

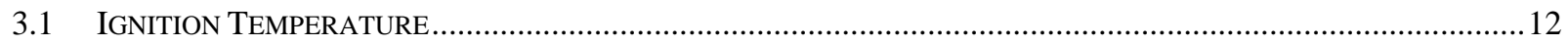

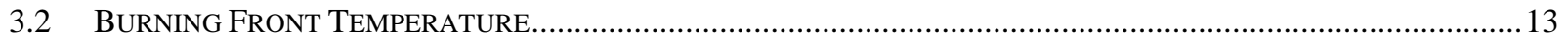

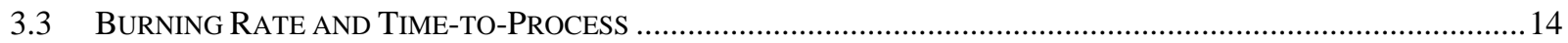

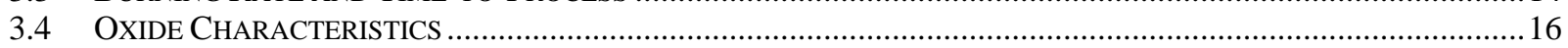

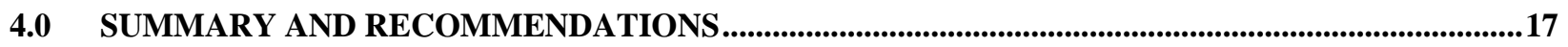

\section{List of Figures}

Figure 1: Schematic representation of metals oxidation: (a) adsorption of oxygen molecule, (b) dissociation of adsorbed oxygen molecule, (c) continued growth by diffusion of oxygen and metal ions through oxide and $(d)$ development of an outer porous layer at the oxide-gas interface and

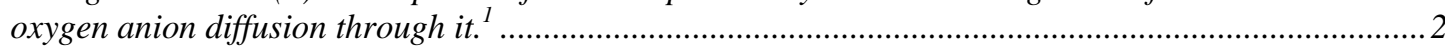

Figure 2: Oxidation kinetics observed for oxidation of metals: (a) power law and linear fit of oxidation behavior and (b) a pseudo-linear rate as described in Figure $1 .^{1}$............................................................

Figure 3: Oxidation of Uranium in Air as a function of time $\left(150-400{ }^{\circ} \mathrm{C}\right)^{2}$............................................................

Figure 4: Activation Energy of Oxidation Processes ${ }^{2}$..........................................................................................5

Figure 5: Typical Temperature Profile of Uranium Oxidation Processes in the $650-800{ }^{\circ} \mathrm{C}$ Range ${ }^{3}$........................ 7

Figure 6: Summary of Measured Oxidation Rates of Uranium Metal..................................................................... 7

Figure 7: Theoretical Oxidation Rate and Burning Temperature for Uranium Metal in Forced Air Convection.

Figure 8: Theoretical Terminal Velocity for Particle Settling Air at 800 C .........................................................8

Figure 9: Flow Diagram for Uranium Metal Oxidation Process...............................................................................9

Figure 10: Oxygen consumption as a function of temperature for Uranium metal Oxidation .....................................16 


\section{Executive Summary}

Published technical information for the process of metal-to-oxide conversion of uranium components has been reviewed and summarized for the purpose of supporting critical decisions for new processes and facilities for the Y-12 National Security Complex. The science of uranium oxidation under low, intermediate, and high temperature conditions is reviewed. A process and system concept is outlined and process parameters identified for uranium oxide production rates. Recommendations for additional investigations to support a conceptual design of a new facility are outlined. 



\subsection{INTRODUCTION}

The current method at the Y-12 National Nuclear Security Complex ("Y-12 Plant") for generating oxide feed for metal purification and recovery involves machining to produce chips, then oxidation of the chips to make oxide. The machining and chip handling steps are labor intensive and are performed in different areas of the plant. To the extent that operations can be consolidated, the resources to produce clean and transport chips can be better utilized for direct production tasks.

In addition, corrosion and security concerns are two challenges in the interim storage of metallic strategic materials and weapons components. The pyrophoric nature of corrosion products and fine particles from uranium-based alloys present safety concerns associated with reactions with liquid water or water vapor. Classified shapes and design of components make storage requirements for weapons components more difficult than conventional oxide based materials. These challenges are eliminated if the components can be converted to oxide powder and stored in a conventional container. The process for the conversion of uranium metal to oxide by burning is possible in an industrial environment.

This report provides a compilation of the technical information and process requirements for the conversion of uranium metal to oxide by burning in air. Several literature documents were reviewed to compile the information in this report. This information will support critical decisions for new facilities and processes at the Y-12 National Security Complex.

\subsection{Background}

The oxidation reaction of a metal (e.g., uranium) with oxygen, $\mathrm{O}_{2}$, is the sum of two separate reactions occurring simultaneously ${ }^{1}$. For the case of a metal, Me, with valence, $\mathrm{n}$, reacting with oxygen, $\mathrm{O}_{2}$, the reactions are:

$$
\text { Oxidation: } \mathrm{Me}=>\mathrm{Me}^{\mathrm{n}+}+\mathrm{ne}^{-} \quad \text { Reduction: } \mathrm{n}_{/ 2} \mathrm{O}+\mathrm{ne}^{-}=>\mathrm{n}_{/ 2} \mathrm{O}^{2-}
$$

The resultant oxide film created is energetically favorable to the metal. When this happens, energy is given off in the form of heat, which raises the temperature of the metal and its surroundings. The phenomenon of oxidation occurs, mechanistically, in several steps. These steps are shown schematically in Figure 1 (a-d). Initially, adsorption of the oxidizing molecule (Figure 1 a) to the surface of the metal starts the reaction, followed by its dissociation and ionization (Figure 1b). Metal cations $\left(\mathrm{Me}^{\mathrm{n}+}\right)$ combine with the oxygen anions $\left(\mathrm{O}^{2-}\right)$ to form oxide. The potential difference created by the charge transfer and concentration gradients in the oxide layer drive ion migration and growth of the oxide film (Figure 1c). Subsequent oxygen molecule adsorption occurs on the oxide surface, followed by dissociation and ionization. The oxygen ions, metal ions or both move through the oxide to combine with the other species and form more oxide. As the oxide grows, the potential difference and concentration gradients become negligible as thickness increases, reducing the driving force for oxide film growth. However, mechanical stress develops in the oxide layer as it thickens. The different densities of the oxide and metal structures result in an interfacial mismatch and an induced stress in the oxide. As the oxide film grows, the stress increases and may become large enough to cause fracture and lead to the formation of a porous, nonprotective layer. In some systems, the stress becomes large enough to cause the oxide to spall away and the process must reinitiate.

As long as the oxide remains adherent and protective, the oxidation rate decreases with time and eventually becomes very small. This behavior is usually best represented by a power law fit of the relationship between weight gain and time $\mathrm{W}=\mathrm{kt}^{1 / 2}$. When the oxide is porous or cracks due to high stress, open pathways allow movement of the oxidizing species and the oxidation rate tends to approach a 
constant with time (i.e., linear relationship, $\mathrm{W}=\mathrm{kt}$ ). In Figure 2a, a graphic representation is shown for each behavior and a combination of these relationships is shown in Figure 2b. Regardless of the form of the equation used to represent the reaction, the rate constant $k$ usually exhibits an Arrhenius relationship with temperature.

$$
\mathrm{k}=\mathrm{A} \exp (-\mathrm{Q} / \mathrm{RT}) \text { where } \quad \begin{aligned}
& \mathrm{k}=\text { oxidation rate constant } \\
& \mathrm{A}=\text { frequency factor } \\
& \mathrm{Q}=\text { the activation energy } \\
& \mathrm{R}=\text { gas constant } \\
& \mathrm{T}=\text { absolute temperature }
\end{aligned}
$$

metal

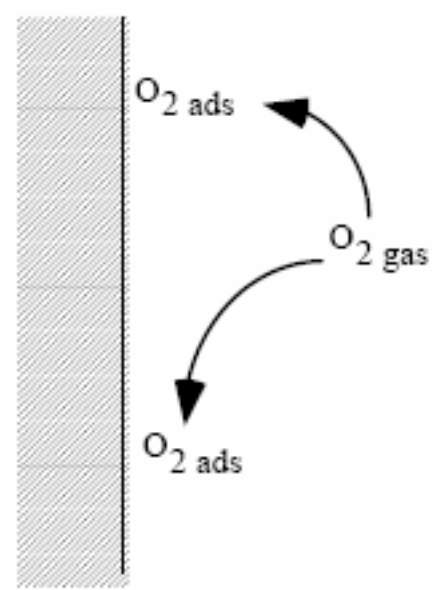

(a)

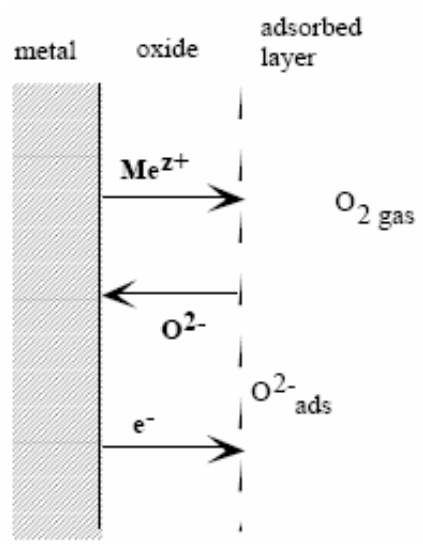

(c)

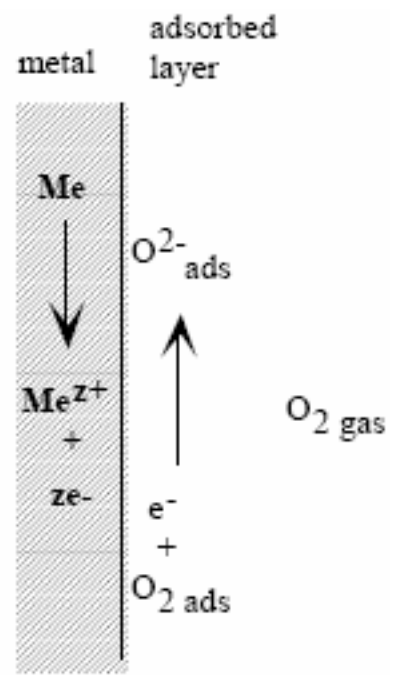

(b)

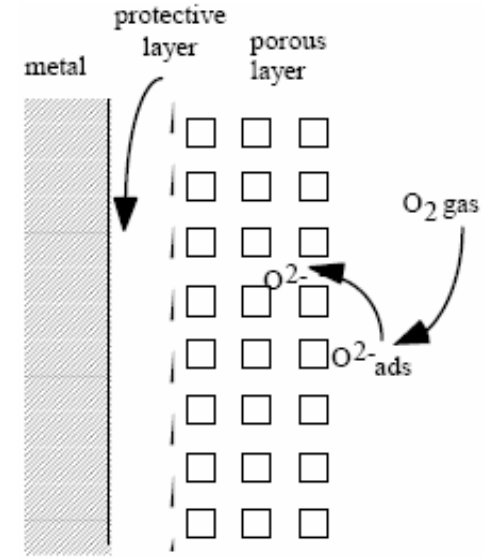

(d)

Figure 1: Schematic representation of metals oxidation: (a) adsorption of oxygen molecule, (b) dissociation of adsorbed oxygen molecule, (c) continued growth by diffusion of oxygen and metal ions through oxide and (d) development of an outer porous layer at the oxidegas interface and oxygen anion diffusion through it. ${ }^{1}$ 


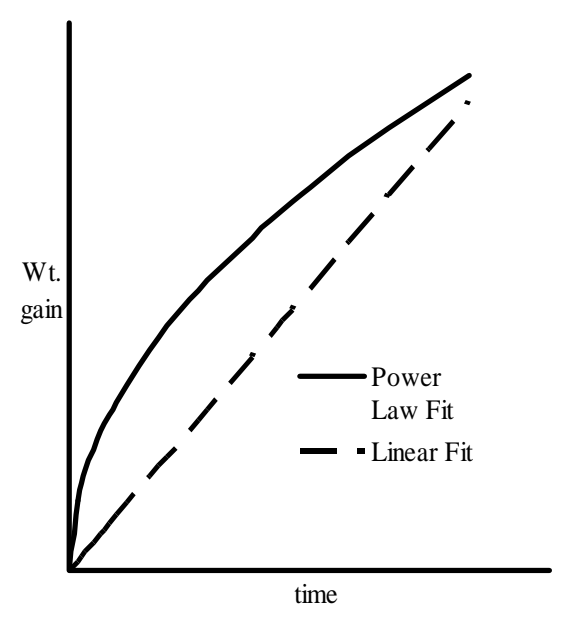

(a)

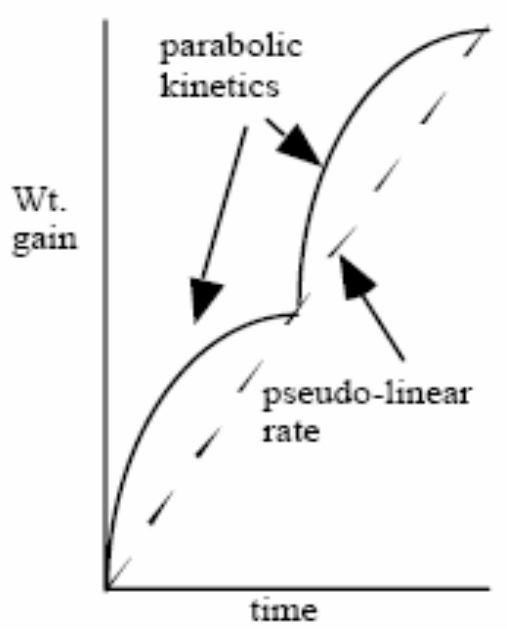

(b)

Figure 2: Oxidation kinetics observed for oxidation of metals: (a) power law and linear fit of
oxidation behavior and (b) a pseudo-linear rate as described in Figure 1.

Uranium metal is pyrophoric in nature and will oxidize readily at near ambient to intermediate temperatures depending on particle size and other factors. Various stoichiometries exist for uranium oxide; the composition of which is largely dependent on temperature and oxygen concentration. The primary oxide phases observed are $\mathrm{UO}_{2}, \mathrm{U}_{3} \mathrm{O}_{8}$ and $\mathrm{UO}_{3}$, but several intermediate stoichiometries and mixtures of phases are also observed. The rate of oxidation also depends on several factors including temperature, environment, particle size and composition.

This report provides a compilation of the technical information and process requirements for the conversion of uranium metal to oxide by burning in air. Several literature documents were reviewed to compile the information in this report. Since oxidation of large monolithic pieces of uranium in air is preferable for the intended process, this report does not focus on the oxidation of powders, but focuses instead on larger samples in flowing air.

\subsection{Literature Overview}

Since the early 1950's the oxidation reaction of uranium metal has been an area of interest in order to provide necessary technical input reactor safety analyses. Several studies were performed in order to determine the effect of particle size, temperature, composition, environment and microstructure on the oxidation rate of uranium metal. Most of the experiments were conducted on small samples exposed to heat in a radiant furnace. Oxidation rates were measured primarily in terms of \% weight gain/ unit time or weight gain/(unit area * unit time) which becomes problematic during oxidation for two reasons. First, the oxide film often spalls off the sample, and hence, it is difficult to accurately measure weight gain. Second, the exposed surface area of the sample is difficult to measure because the roughness of the oxidemetal interface during the test is unknown. In addition, the extent of the oxidation process is dependent on the stoichiometry of the oxide phase(s) present; oxide stoichiometry affects the application of the rate of oxidation toward process cycle time predictions. Finally, some confusion may exist in that rates are reported as mass $\mathrm{O}_{2} /$ (unit area $*$ unit time) while others report mass $\mathrm{U} /$ (unit area $*$ unit time) (mass $\mathrm{U} \sim 5$ $8 \mathrm{x}$ mass $\mathrm{O}_{2}$ for the oxidation process). This being noted, a wealth of data exists for oxidation uranium 
metal and alloys at low, intermediate and elevated temperatures in air. A brief description of these results is summarized herein.

\subsubsection{Low Temperature Oxidation: (i.e.100-300 ${ }^{\circ} \mathrm{C}$ )}

One of the earliest resources for oxidation behavior of uranium was compiled by Bagley and Oliver ${ }^{2}$. In their study of oxidation kinetics, they investigated the role of time, temperature, environment and oxide composition in oxidation kinetics. Oxidation experiments were conducted in pure oxygen, steam and dry air at temperatures between 100 and $500^{\circ} \mathrm{C}$. They noted several important observations when summarizing their low temperature oxidizing experiments. First, the nature of the oxide changes as temperature increases. At $190{ }^{\circ} \mathrm{C}$ and below the oxide present on the surface is primarily $\mathrm{UO}_{2}$. From 200 to $250{ }^{\circ} \mathrm{C}$, the character of the oxide is mixed $\left(\mathrm{UO}_{2}\right.$ and $\left.\mathrm{U}_{3} \mathrm{O}_{8}\right)$ and above $250{ }^{\circ} \mathrm{C}$, only $\mathrm{U}_{3} \mathrm{O}_{8}$ is present. Isaacs and Wanklyn ${ }^{3}$ observed similar behavior in their oxidation studies at $300{ }^{\circ} \mathrm{C}$. They also noted the presence of cracking in oxide films at all temperatures above $150{ }^{\circ} \mathrm{C}$. In addition, above $270{ }^{\circ} \mathrm{C}$ the oxide scale readily spalls off as a granular powder (decreasing in particle size as temperature is increased). The oxidation rates measured are shown in Figure 3. The rate of oxidation measured is almost constant with time for a given temperature so a linear fit to the data yields rates that vary between $3 \mathrm{mg} \mathrm{O} / 2 / \mathrm{cm}^{2} / \mathrm{hr}$ at $150{ }^{\circ} \mathrm{C}$ and $120 \mathrm{mg} \mathrm{O}_{2} / \mathrm{cm}^{2} / \mathrm{hr}$ at $300^{\circ} \mathrm{C}$. The Arrhenius treatment of oxidation rate constants (see Figure 4) revealed that three different processes controlled the rate of oxidation, each having their own activation energy (see Table 1). The three temperature regimes corresponded (roughly) to the temperature regimes of the different oxides mentioned, previously.

\section{Table I: Activation Energy for oxidation rates from Figure 4}

\begin{tabular}{|l|l|l|}
\hline Temperature & $\begin{array}{l}\text { Oxide Phase(s) } \\
\text { Present }\end{array}$ & $\begin{array}{l}\text { Activation Energy } \\
\text { k cal/mole }\end{array}$ \\
\hline$<190{ }^{\circ} \mathrm{C}$ & $\mathrm{UO}_{2}$ & 13.3 \\
\hline $190-225^{\circ} \mathrm{C}$ & $\mathrm{UO}_{2}$ and $\mathrm{U}_{3} \mathrm{O}_{8}$ & 25 \\
\hline $225-270^{\circ} \mathrm{C}$ & $\mathrm{U}_{3} \mathrm{O}_{8}$ & 11.5 \\
\hline
\end{tabular}




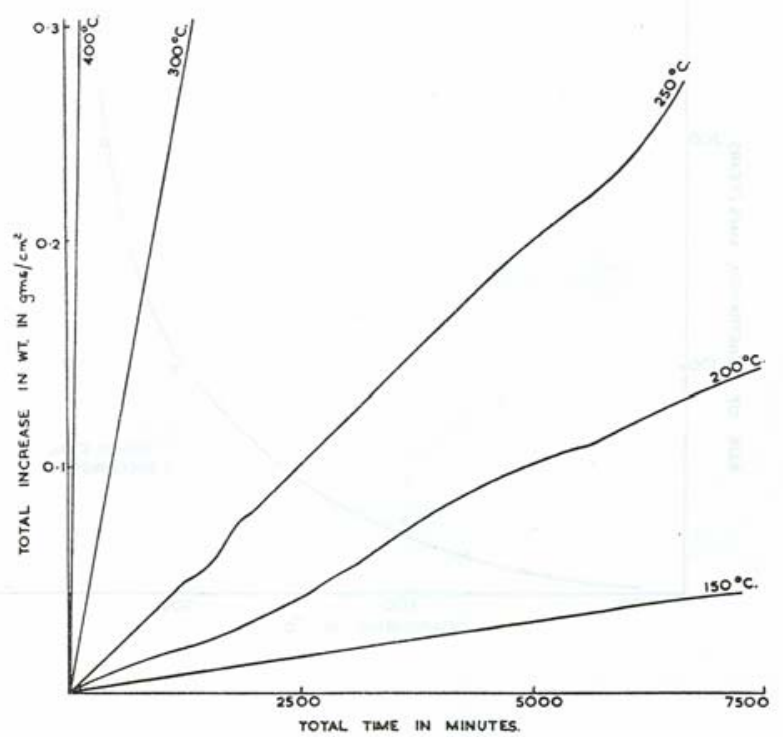

Figure 3: Oxidation of Uranium in Air as a function of time $\left(150-400{ }^{\circ} \mathrm{C}\right)^{2}$

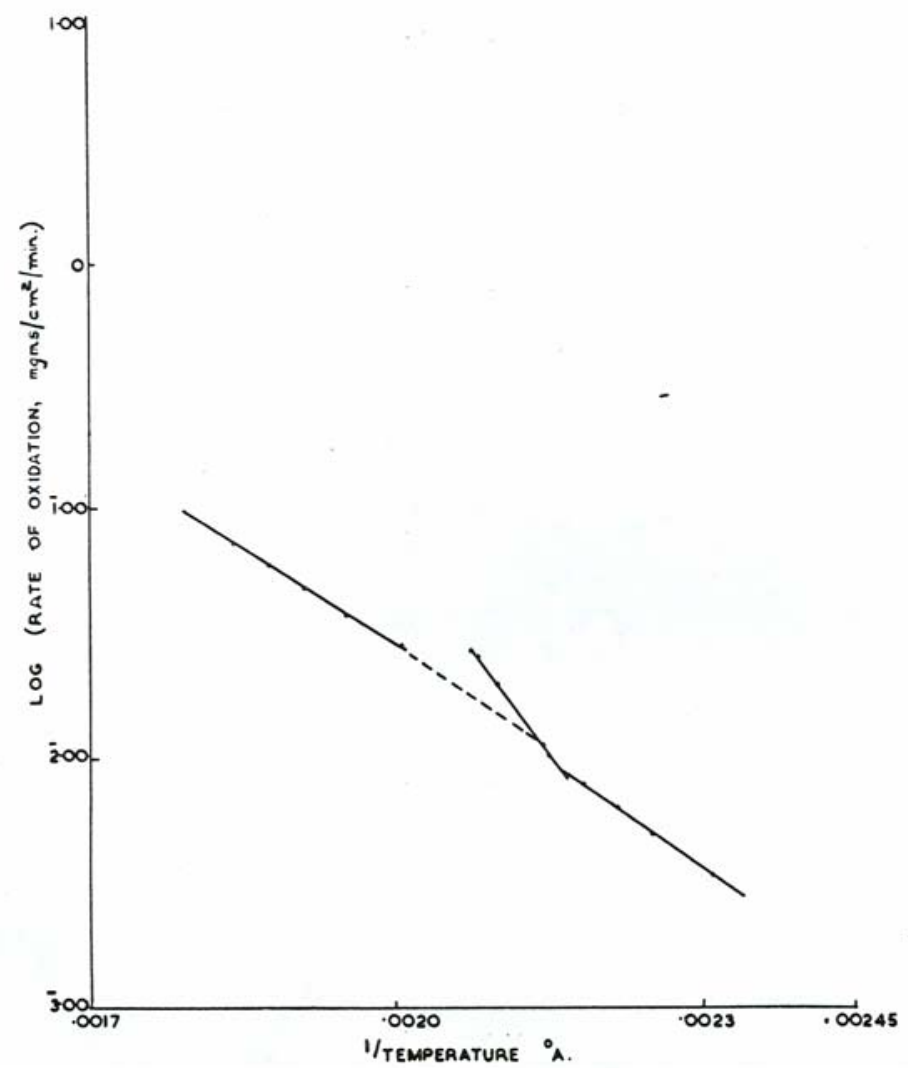

Figure 4: Activation Energy of Oxidation Processes ${ }^{2}$ 


\subsubsection{Intermediate Temperature Oxidation: (i.e.300-650 ${ }^{\circ} \mathrm{C}$ )}

At higher temperatures the oxidation occurs more rapidly, and the appearance of the oxide was dependent on temperature. Isaacs and Wanklyn ${ }^{3}$ reported that, in this range of temperatures, the oxide becomes more dense and sintered. As temperatures increased, the description of oxide changed from granules $\left(300-500{ }^{\circ} \mathrm{C}\right)$ to platelets or flakes $\left(500-530{ }^{\circ} \mathrm{C}\right)$ to complete layers of firm oxide $\left(530-650{ }^{\circ} \mathrm{C}\right)$. They also reported the fraction of oxide that had spalled away (which was significant). In general, the oxide formed from 300 to $450{ }^{\circ} \mathrm{C}$ was non-protective and spalled away readily when tapped or as a result of thermal gradients. From 450 to $650^{\circ} \mathrm{C}$ the oxide became dense and less likely to spall off the sample. Cyclic, self heating was noted during the experiment but did not result in sustained ignition of the metal. In general, the test temperatures, in which dense oxide layers form, exhibited less thermal cycling than the temperatures which produced the granular non-protective oxide. Hence, self-heating was attributed to the exposure of new, unoxidized metal to the environment when the oxide spalls away.

Measured rates of oxidation vary and are dependent on many factors, including particle size, gas flow rate, composition and temperature. In general, oxidation rates increase with gas flow rate and temperature. They decrease as particle size increases and composition deviates from pure uranium. Oxidation rates were measured at $300{ }^{\circ} \mathrm{C}$ ranging from $3-120 \mathrm{mg} \mathrm{O} / \mathrm{cm}^{2} / \mathrm{hr}$ but increase to as much as $146 \mathrm{mg} \mathrm{O} \mathrm{O}_{2} / \mathrm{cm}^{2} / \mathrm{hr}$ at $410{ }^{\circ} \mathrm{C}$. Near $450{ }^{\circ} \mathrm{C}$, a discontinuity in the relationship between oxidation rate and temperature is observed and the rates are reduced, slightly, at this temperature ( $100 \mathrm{mg} \mathrm{O} / \mathrm{cm}^{2} / \mathrm{hr}$ ). From 450 to $650{ }^{\circ} \mathrm{C}$, the oxidation rates increase, once again; climbing to as high as $300 \mathrm{mg} \mathrm{O} / \mathrm{cm}^{2} / \mathrm{hr}$ at $650^{\circ} \mathrm{C}$.

\subsubsection{Elevated Temperature Oxidation: (i.e. $>650^{\circ} \mathrm{C}$ )}

As temperature is increased the oxidation occurs even more rapidly but self sustaining ignition of monolithic samples was not observed. In general, the reaction had to be sustained by the surrounding heat source, although cyclic temperature excursions do occur. Figure 5 shows an example of these thermal excursions. The oxide was observed to be more plate-like and thicker as temperature increased. Isaacs and Wanklyn ${ }^{3}$ report that the oxide forms an adherent skin, but the occurrence of deep fissures allows oxidation to continue. Bagley and Oliver $^{2}$ noted that oxidation in this temperature range is so rapid that the oxide disintegrates. Oxidation rates were from 300 to over $1000 \mathrm{mg} \mathrm{O}_{2} / \mathrm{cm}^{2} / \mathrm{hr}$ at $1000{ }^{\circ} \mathrm{C}$. A summary of oxidation rates from numerous studies is presented for various temperatures in Figure 6.

\subsubsection{Gas Velocity Effects on Oxidation Rate:}

The majority of reported oxidation rates were conducted in low to moderate gas flow rates. Forced convection is important in the oxidation process in order to increase the rate of oxygen to the reaction. In flowing air, oxidation rates have been calculated to reach as high as $3800 \mathrm{mg} \mathrm{O}_{2} / \mathrm{cm}^{2} / \mathrm{hr}^{4}$ (see Figure 7). However this may not be a practical operating parameter. Too high a flow rate may entrain oxide particles that have spalled away from the sample. Figure 8 graphically displays the terminal velocity of spherical particles in air at $800 \mathrm{C}$. The terminal velocity is a measure of how easily particles settle out of an air stream. In an air stream oriented directly upward at a particle's terminal velocity it ceases to fall downward and does not settle. When comparing Figures 7 and 8, it becomes clear that the size of particle potentially entrained by the air stream becomes significant even at gas velocities as low as $10 \mathrm{~cm} / \mathrm{sec}$. Unfortunately, the particle size distribution for oxidation of uranium does not appear in previous studies but diameters of $10 \mu \mathrm{m}$ or less would be expected. Particle size distribution can be characterized upon start up and flow rate can be adjusted accordingly. 
Alternatively, the flow rate must be high enough to provide enough oxygen to allow the oxidation reaction to proceed. The volumetric flow rate required for a given oxidation rate will depend on several factors but the volumetric flow rate can not be less than that of the oxidation rate. Volumetric flow rates of 1 to 12 liter/ $\mathrm{cm}^{2} \mathrm{hr}$ at STP would supply enough oxygen for the rates shown in Figure 7. Depending on the size of the reaction chamber this would result in forced convection gas velocities of $>1 \mathrm{~cm} / \mathrm{sec}$.

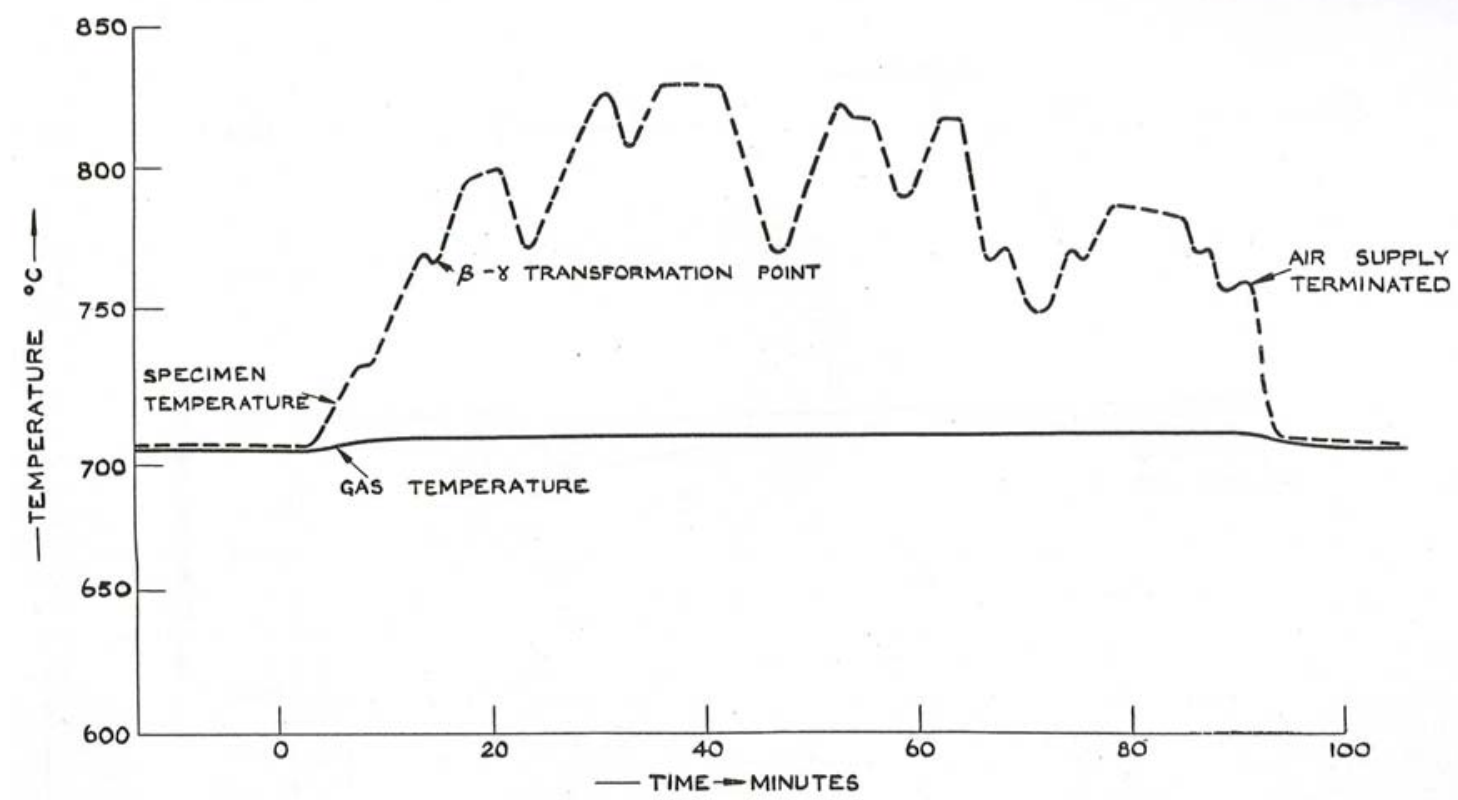

Figure 5: Typical Temperature Profile of Uranium Oxidation Processes in the $650-800{ }^{\circ} \mathrm{C}$ Range ${ }^{3}$.

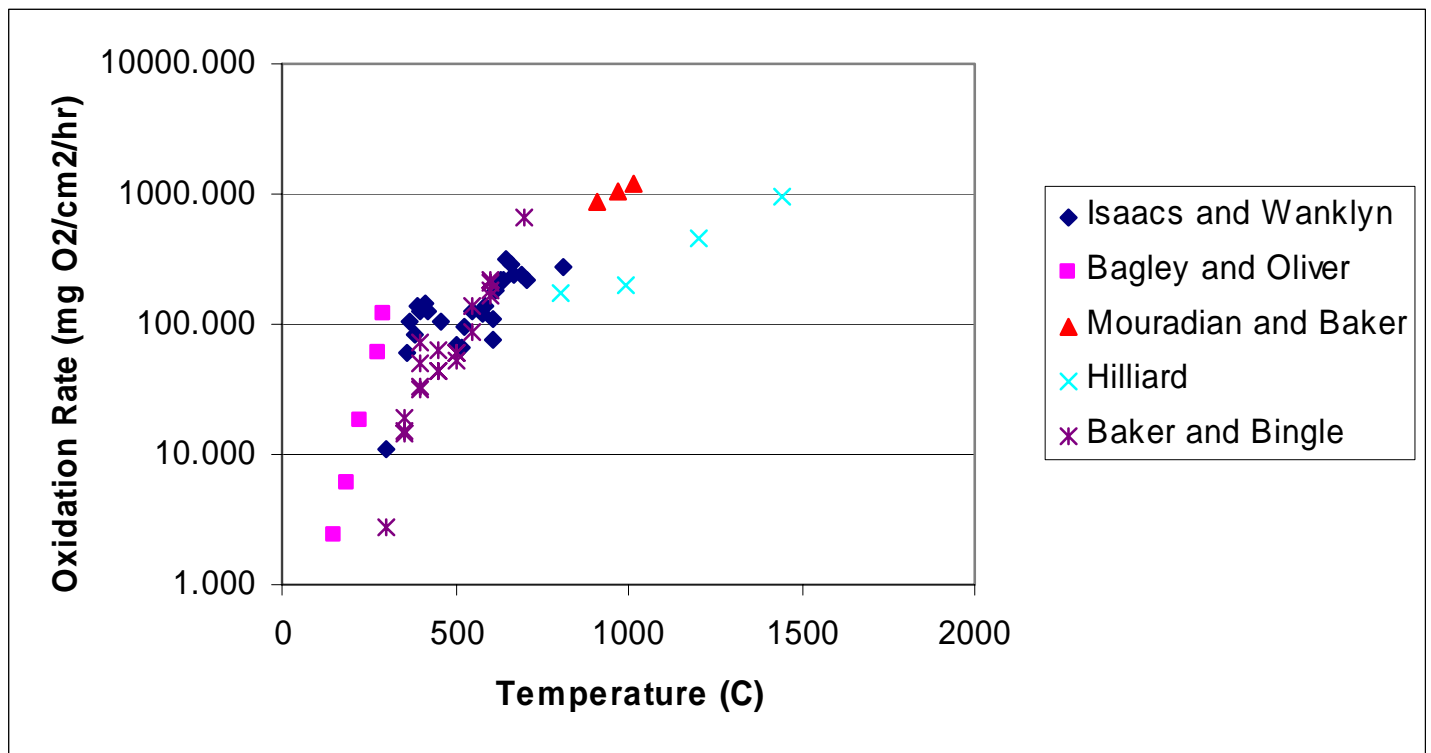

Figure 6: Summary of Measured Oxidation Rates of Uranium Metal 


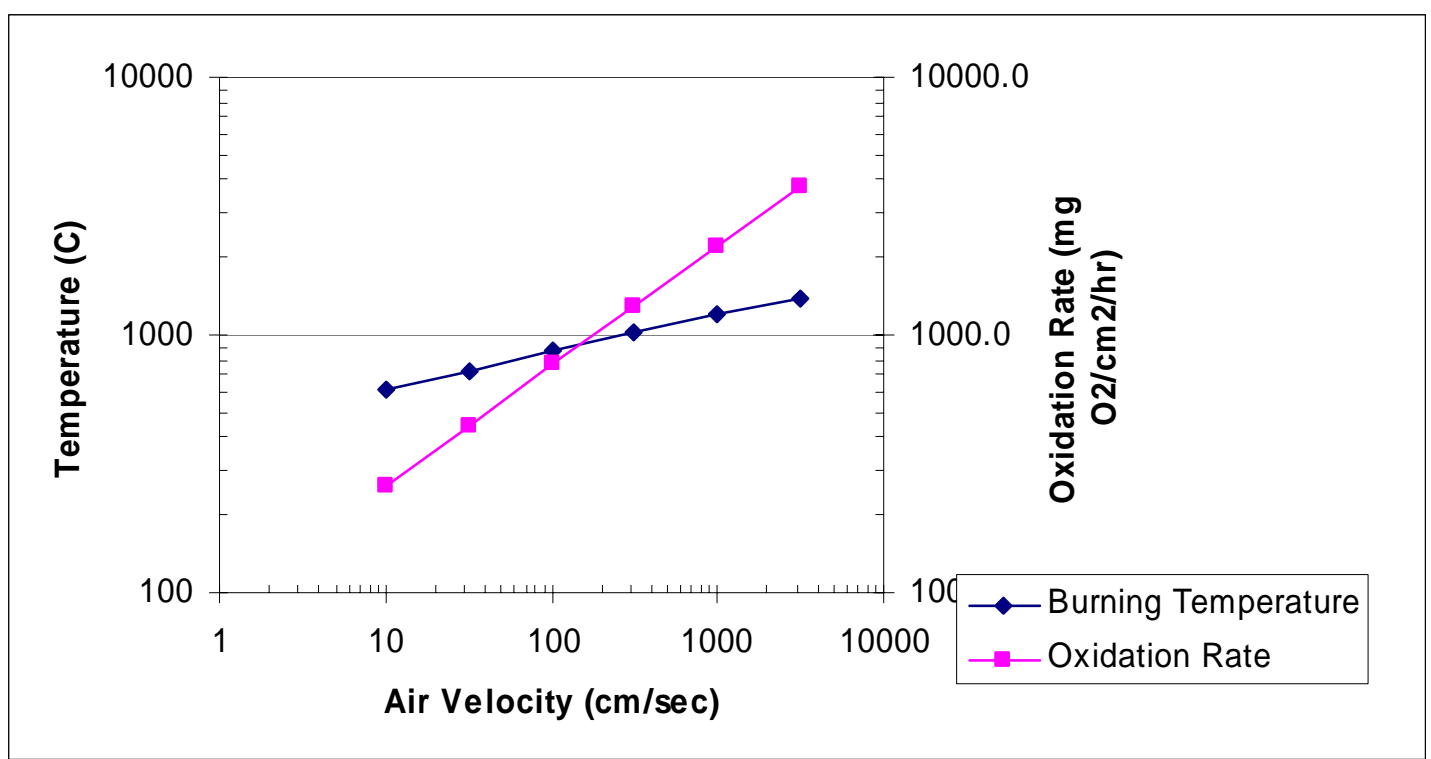

Figure 7: Theoretical Oxidation Rate and Burning Temperature for Uranium Metal in Forced Air Convection.

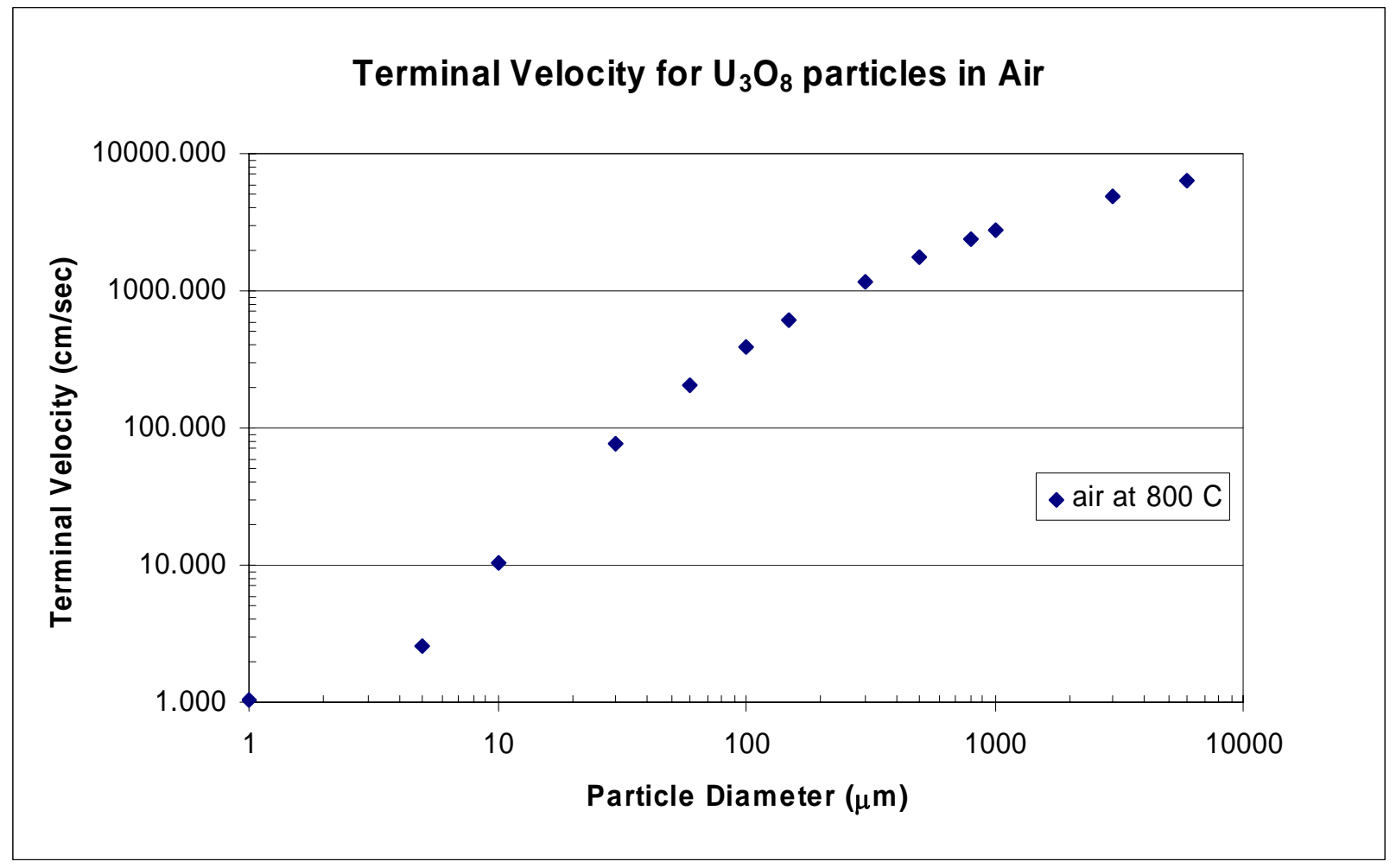

Figure 8: Theoretical Terminal Velocity for Particle Settling Air at $800 \mathrm{C}$. 


\subsection{GENERAL PERFORMANCE REQUIREMENTS FOR SYSTEM}

Considering the previous studies summarized above it is possible to design a controlled process for the conversion of uranium metal to uranium oxide. The fundamental concept would involve a furnace that would supply enough heat and $\mathrm{O}_{2}$ to change the form of uranium from metal to oxide (see Figure 9). The process feed could consist of large monolithic pieces of metal but could also be re-sized to improve the process kinetics. The oxidation would be performed as a batch process. A process chamber is required that is capable of isolating the products from the environment and workers. The products will be consolidated and stored in a safe configuration. The basic performance requirements of a process are summarized in this section.

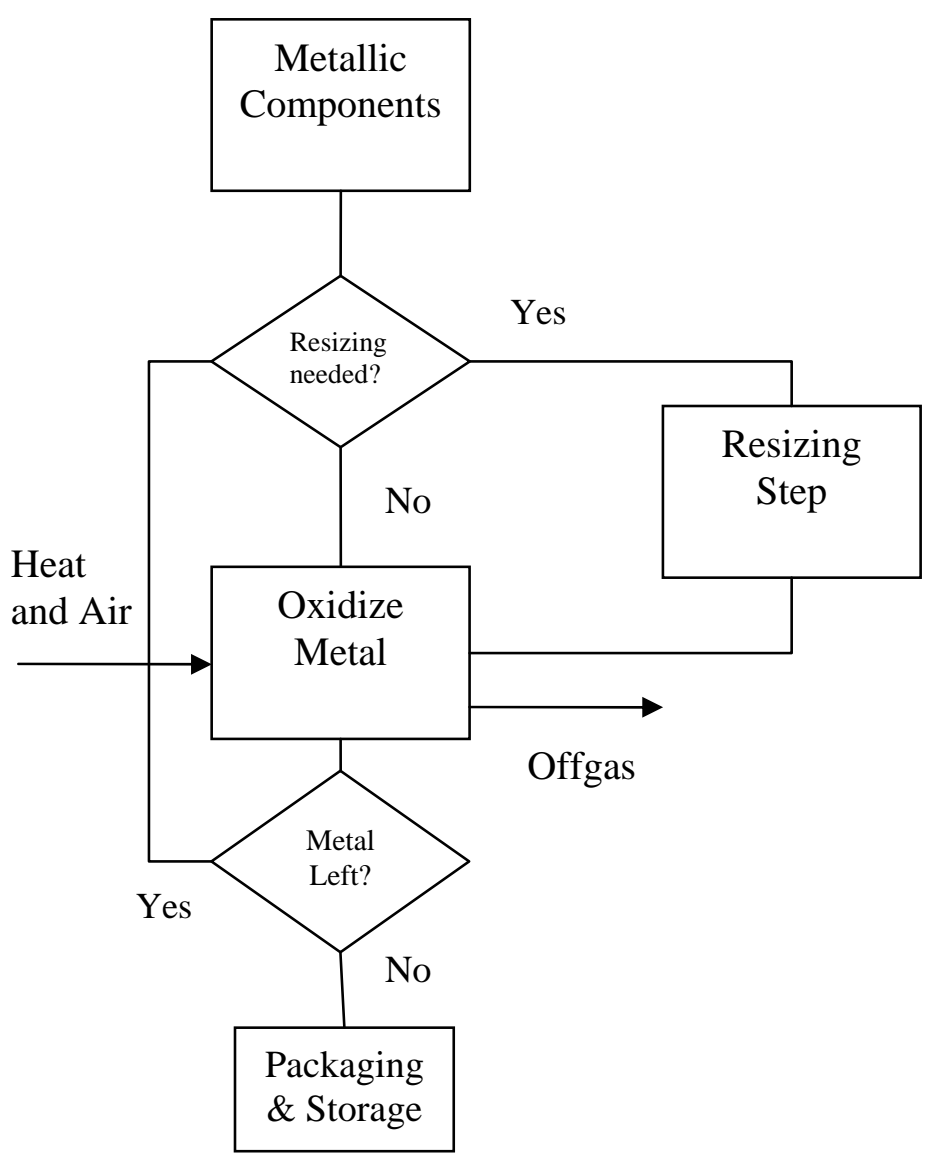

Figure 9: Flow Diagram for Uranium Metal Oxidation Process

\subsection{Source Material Input Variables}

The source material feed will be uranium metal in the form of components of various shapes and sizes. The surface area to mass ratio is well below that of the reports reviewed above. Specifically, the lowest surface area to mass ratio is $0.2 \mathrm{~cm}^{2} / \mathrm{g}$. The kinetics of this oxide conversion can be increased by the resizing of these components. A crop shear is one way to resize these components but other suitable methods involve cutting, electro-discharge machining and milling. However, machining and milling 
necessitate cooling in order to prevent premature, uncontrolled oxidation. This may be impractical from a process standpoint because it would require a cleaning step prior to the oxidation.

Other input variables are heat and the oxygen source. The heat will be provided by a furnace. The most practical oxygen source is air. In applications with strict product purity requirements, conditioning of the air prior to introducing it to the furnace would be considered. In this application, purity of the oxide product is not a primary consideration, so treatment of the air is unnecessary. Researchers at Argonne National Laboratory (ANL) investigated the effect of moisture in air on the ignition temperature* and oxidation rate of uranium and found no significant effect. ${ }^{5,6}$ In contrast, Bagley and Oliver report oxidation rates in steam that are 3 to 4 times higher than the rates they report for air. ${ }^{2}$ Advantages of using a steam atmosphere in a furnace must be weighed against operational and safety issues associated with the use of steam with uranium at high temperatures in enclosed equipment.

The volume flow rate of the oxygen source will be determined based on the desired oxidation rate of the material feed and the characteristics of the oxide product. The gas velocity in the reaction chamber should be low enough to minimize the amount of oxide particles entrained in the off-gas system. Based on the maximum oxidation rate reported in the literature and a $12 \mathrm{~kg}$ cylinder the volume flow rate would not need to exceed $10 \mathrm{ft}^{3}$ of air/min.

* "Ignition temperature" as used in the ANL reports, refers to the temperature at which the slope of the specimen temperature versus time curve increases sharply relative to the furnace temperature trace, indicating the onset of self-heating of the specimen.

\subsection{Furnace Operating Conditions}

The central component to this process is the oxidizing furnace. To perform its desired function this furnace must be large enough to hold the largest component designated for conversion without resizing. The proposed process would involve a slow ramp to temperature and an isothermal hold at a temperature between 700 and $1000{ }^{\circ} \mathrm{C}$. The duration of the hold would depend on several variables but would range from hours to days. Although the furnace itself would not need a temperature capacity above $1000{ }^{\circ} \mathrm{C}$, the furniture (i.e., crucible or specimen platform) inside would need to withstand higher temperatures and the thermal gradients associated with the oxidation process. Bulk metal oxidation temperatures in excess of $1800{ }^{\circ} \mathrm{C}$ have been measured in the literature ${ }^{7,8}$ so the primary container must be able to withstand these temperatures. Thermal control is needed to ensure the process reaction occurs in the desired range. The reaction chamber must be capable of running in air or oxidizing environment. There must be an ability to minimize the spread of contamination and maintain a mass balance of input feeds for process control. Therefore, product hold-up in the furnace and contamination of the product by furnace materials of construction should be minimized.

The means of placing metal into the furnace and removing oxide from the furnace are important design considerations from accountability and radiological control perspectives. Metal can be placed in the furnace from a glovebox or enclosure in a straightforward manner. The removal of the oxide product is more problematic because of the potential for airborne contamination. To the extent that the furnace design facilitates the transfer of oxide into a standard storage container, radiological exposure and contamination issues will be minimized. Direct transfer from the oxidation chamber to a container is preferred. If the furnace must be opened for transfer of the oxide after it cools, then a dry vacuum transfer system or something similar might be considered. Manual transfer from a crucible or a reaction vessel containing the oxide product to an approved container is the least desirable option. Allowance must be 
made for the volume increase of the metal on oxidation, i.e., the volume of the oxide product will occupy 3 to 4 times the volume of the metal feed.

Heat generated by the furnace and the reaction must be removed from the enclosure/glove box and from the room in which the equipment is installed. Filtration is required to contain contamination in offgas from the reaction chamber.

\subsection{Volume/Batch Size and Throughput}

The batch size of the process will be determined by the availability of feed material and demand for oxide product. If the furnace is used to oxidize fissile uranium, the batch size will be limited by criticality safety considerations. Limitations in batch size will be controlled by the thermal and size limitations of the furnace. If high throughput is an important consideration, multiple small furnaces can be deployed and run in parallel.

\section{$2.4 \quad$ Product Quality}

The level of contaminants in the oxide product depends on the quality of the metal feed and contaminants in the oxidizing atmosphere. For oxide that is destined for purification and recovery, the level of contaminants imparted by the oxidation process is not particularly important. For oxide that must meet a customer purity specification, control of the atmosphere in the furnace may be an important variable. In general, concerns associated with of atmospheric moisture and trace quantities of unreacted metal are not a concern for applications at the Y-12 Plant. In the case of plutonium storage, residual moisture in oxides combines with other impurities to cause corrosion of the storage vessel and can lead to hydrogen generation due to radiolysis of water ${ }^{9}$. This should not be a concern for uranium because its decay rate is small compared to plutonium. Depending on the interim storage conditions, moisture and/or impurity tolerances may be implemented by controlling the feed materials and gas purity.

The degree of "sintering" of the oxide affects the ease with which it can be dissolved and is an important process consideration. As was indicated in Section 1.2.3 of this report and by most researchers who evaluated oxidation at furnace temperatures over $800^{\circ} \mathrm{C}$, the oxide product becomes scaly, harder, and takes on a "sintered" appearance at high temperature. Such oxide is less reactive, i.e., more difficult to dissolve, than oxide produced at lower temperatures. The trade-off between higher oxidation rates at higher temperatures versus more reactive oxide at lower temperatures may warrant further evaluation. Such an evaluation could be performed as part of an experimental program or it could be optimized during operations

\section{$2.5 \quad$ Process Control}

Process control will be accomplished by controlling the furnace temperature and gas flow rate. Ultimately the control of these variables will determine the cycle time of the process. The monitoring of temperature could be accomplished in several ways. The method would depend on the precision needed. If process cycle time is not important the process could be controlled using the furnace control thermocouples. If process cycle time needs to be minimized, additional temperature measurement needs to be installed in the reaction chamber. Optical pyrometry could be utilized for a less intrusive measurement of temperature. 


\subsection{Waste Stream}

Waste stream issues involved with the process are primarily the off-gas and contamination. Furnace design and operating parameters can be adjusted to minimize both of these.

\subsection{BURNING RATE AND TEMPERATURE}

\subsection{Ignition Temperature}

Ignition temperature is defined as the temperature by which the oxidation reaction becomes selfsustaining. The ignition temperature of uranium metal is dependent is primarily dependent on particle size. Studies on spherical powders gave demonstrated that uranium would ignite as low as $250^{\circ} \mathrm{C}$ and that the ignition temperature was inversely proportional to the surface area ${ }^{10}$. Baker et $\mathrm{al}^{7}$. compiled data from ignition experiments on foil, wire and bulk samples, and reported ignition temperatures ranging from as low as $350^{\circ} \mathrm{C}$ for uranium foil (surface area $=49 \mathrm{~cm}^{2} / \mathrm{g}$ ) in air up to $700{ }^{\circ} \mathrm{C}$ for single cubes (surface area $=0.38 \mathrm{~cm}^{2} / \mathrm{g}$ ). Ignition temperatures measured in air were slightly higher than those measured in pure oxygen. Figure 10 illustrates this relationship between surface area and ignition temperature, as reported in this study. An abrupt transition is observed for surface areas in the vicinity of 2 and $5 \mathrm{~cm}^{2} / g$ for pure oxygen and air, respectively. Hence, a drastic drop in the ignition temperature has been observed for uranium pieces that exhibit surface area values above this transition.

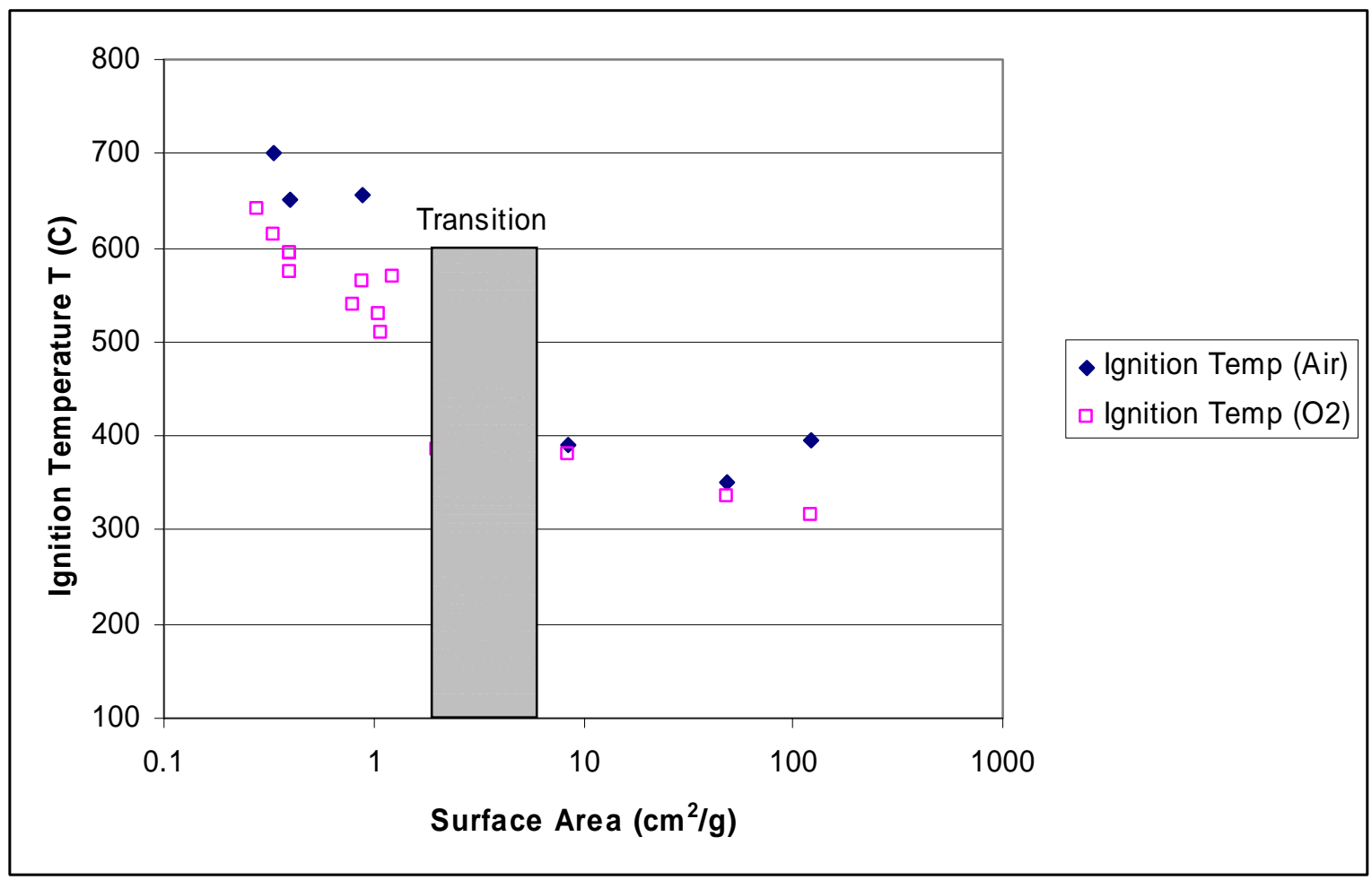

Figure 10: Relationship between Surface area and Ignition temperature ${ }^{7}$ 


\subsection{Burning Front Temperature}

Burning front temperature is the temperature at which the oxidation reaction heats the metal/oxide interface during the reaction. The temperature of this reaction front is dependent on a balance between the heat generated by the oxidation reaction and the heat lost from conduction into the metal, radiation to the surrounding environment and convection to the atmosphere. Experimentally, several variables can change the dominant mechanisms controlling the burning front temperature. Variables such as sample geometry, thickness of the oxide layer, gas velocity, and reaction rate can set up conditions which make one heat sink mechanism controlling (i.e., limiting) and determine the inevitable burning front temperature. Mouradian and Baker ${ }^{4}$ modeled the oxidation rate for uranium and zirconium for samples of specific geometries. Their model balanced heat generated from the oxidation reaction with losses due to radiation and convection as a function of sample size. In their model, the oxidation reaction rate was limited by diffusion of oxygen through the nitrogen rich atmosphere adjacent to the surface. Heat losses due to radiation and convection are affected by the emissivity $(\varepsilon)$ of the surface oxide layer and convective cooling of gases across exposed surfaces. In the model, burning front temperature increases as gas velocity increases and of sample length scale (size) decreases. For example, burning front temperatures for cylinders in conditions suitable for natural convection vary between $907^{\circ} \mathrm{C}(10 \mathrm{~cm}$ in diameter) to over $2100{ }^{\circ} \mathrm{C}(0.02 \mathrm{~cm}$ in diameter $)$. In addition, the rate of oxidation also increases with burning front temperature (see Table 2)

Table II: Theoretical Burning Front Temperatures and Rates for Different Shapes of Uranium Metal under natural convection conditions. ${ }^{4}$ (rate equations in bold were used to calculate time to complete oxidation in Figure 11)

\begin{tabular}{|c|c|c|c|c|c|c|}
\hline $\begin{array}{l}\text { Characteristic } \\
\text { dimension }\end{array}$ & \multicolumn{2}{|c|}{$\begin{array}{l}\text { Cylinder (diameter) } \\
\text { Burning Temp, Rate }\end{array}$} & \multicolumn{2}{|c|}{$\begin{array}{l}\text { Foil (height) } \\
\text { Burning Temp, Rate }\end{array}$} & \multicolumn{2}{|c|}{$\begin{array}{l}\text { Sphere (diameter) } \\
\text { Burning Temp, Rate }\end{array}$} \\
\hline $\mathrm{L}(\mathrm{cm})$ & ${ }^{\circ} \mathrm{C}$ & $\mathrm{g} \mathrm{O} 2 / \mathrm{hr} / \mathrm{cm} 2$ & ${ }^{\circ} \mathrm{C}$ & $\mathrm{g} \mathrm{O} 2 / \mathrm{hr} / \mathrm{cm} 2$ & ${ }^{\circ} \mathrm{C}$ & $\mathrm{g} \mathrm{O} 2 / \mathrm{hr} / \mathrm{cm} 2$ \\
\hline 0.05 & 1791 & 9.540 & 1847 & 10.800 & 2297 & 25.920 \\
\hline 0.5 & 1235 & 2.382 & 1289 & 2.826 & 1442 & 4.026 \\
\hline 1 & 1135 & 1.800 & 1189 & 2.142 & 1297 & 2.790 \\
\hline 10 & 907 & 0.876 & 967 & 1.050 & 1012 & 1.182 \\
\hline $\begin{array}{l}\text { Power law fit } \\
(0.2<\mathrm{L}<20) \\
\mathrm{R}=\mathrm{AL}^{-\mathrm{B}}\end{array}$ & & $=1.959 \mathrm{~L}^{-0.3704}$ & & $=2.271 \mathrm{~L}^{-0.3461}$ & & $=3.213 \mathrm{~L}^{-0.4691}$ \\
\hline
\end{tabular}

Other modeling approaches assume different components of the heat balance to be dominant. Laurinat ${ }^{11}$ developed a model for oxidation plutonium-uranium alloys which was termed ash-layer diffusion. In this model, the heat generated for the oxidation was balanced with losses due to conduction of heat away from the burning front into the metal sample. Convection and radiation were assumed to be negligible because the surface oxide layer reduced these losses to effectively zero. The surface oxide layer also reduces the rate of oxidation: the rate is limited by oxygen diffusing through the porosity in the oxide layer rather than through a nitrogen rich gas layer. In this model, the burning front temperature differs from that of the Mouradian model because of the oxidation rate starts off high and slows down as the oxide layer thickens. A maximum burning front temperature is calculated (called the maximum postignition temperature) 


\subsection{Burning Rate and Time-to-Process}

The burning rate will be dependent on several variables. Several studies published rates of $\mathrm{O}_{2}$ consumption as a measure of oxidation rates. Previous work reported that the surface area of an oxidizing object remains constant and the oxidation behavior can be assumed to be linear ${ }^{10}$. Hence, the process cycle time may be approximated to the first order using the relationship:

$$
\mathrm{t}_{\mathrm{f}}=\frac{\mathrm{M}_{\mathrm{O} 2}}{\mathrm{R}_{\mathrm{O} 2} * \mathrm{~S}_{\mathrm{U}}}
$$

where $t_{\mathrm{f}}$ is the time to process completion

$\mathrm{M}_{\mathrm{O} 2}$ is the total mass of oxygen required for process

$\mathrm{R}_{\mathrm{O} 2}$ is the oxygen consumption rate

$\mathrm{S}_{\mathrm{U}}$ is the sample surface area

However, this value for process time is not conservative and may be more accurately reflected if the surface area is allowed to decrease at a rate proportional to the length scale. In addition, the predicted rate increases as the sample gets smaller ${ }^{4}$. The rate change was interpolated between data points using a power law fit of the rate data as a function of $\mathrm{L}$ and is given in Table II. Both of these modifications are reflected in the equation.

$$
\mathrm{t}_{\mathrm{f}}=\frac{\mathrm{M}^{\mathrm{i}} \mathrm{O} 2_{\mathrm{O} 2}^{\mathrm{O}} * \mathrm{~S}_{\mathrm{U}}^{\mathrm{i}}}{\mathrm{R}_{\mathrm{O}}}
$$

where $\mathrm{M}_{\mathrm{O} 2}^{\mathrm{i}}, \mathrm{R}_{\mathrm{O} 2}^{\mathrm{i}}$ and $\mathrm{S}_{\mathrm{U}}^{\mathrm{i}}$ are the oxygen mass, consumption rate and surface area as a function of $\mathrm{L}$

The mass of oxygen $\left(\mathrm{M}_{\mathrm{O} 2}^{\mathrm{i}}\right)$ required to oxidize the sample at any given time would be proportional to the stoichiometry of the oxide. $\mathrm{U}_{3} \mathrm{O}_{8}$ is $15.2 \%$ by weight oxygen, so $20 \mathrm{~kg}$ of uranium would need 3.58 $\mathrm{kg}$ of oxygen for complete conversion $(15.2 * 20 \mathrm{~kg} / 84.8)$. The mass of the initial uranium piece is related to its volume $\left(\mathrm{V}_{\mathrm{U}}^{\mathrm{i}}\right)$ and density $\left(\rho_{\mathrm{U}}\right)$. Hence, for the $\mathrm{U}_{3} \mathrm{O}_{8}$ stoichiometry

$$
\mathrm{M}_{\mathrm{O} 2}^{\mathrm{i}}=\frac{15.2 * \rho_{\underline{\mathrm{U}}} * \mathrm{~V}^{\mathrm{i}} \underline{\mathrm{U}}}{84.8}
$$

The surface area $\left(\mathrm{S}_{\mathrm{U}}^{\mathrm{i}}\right)$ of the uranium piece and volume $\left(\mathrm{V}_{\mathrm{U}}^{\mathrm{i}}\right)$ at any given time can be related to its dimension (L) for a given geometry. The ratio between volume and surface area is also expressed as a function of $\mathrm{L}$.

Cylinder ( $\mathrm{L}$ = length and diameter)

$$
\frac{V_{U}^{i}}{S_{U}^{i}}=\frac{\pi \frac{L^{2}}{4} L}{2 \pi \frac{L^{2}}{4}+\pi L^{2}}=\frac{L}{6}
$$

Sphere $(\mathrm{L}=$ diameter $)$

$$
\frac{V_{U}^{i}}{S_{U}^{i}}=\frac{\frac{4}{3} \pi \frac{L^{3}}{8}}{4 \pi \frac{L^{2}}{4}}=\frac{L}{6}
$$




$$
\text { Cube or Sheet }(\mathrm{L}=\text { length and width, thickness }=\mathrm{L} / \alpha) \frac{V_{U}^{i}}{S_{U}^{i}}=\frac{\frac{L^{3}}{\alpha}}{2 L^{2}+4 \frac{L^{2}}{\alpha}}=\frac{L}{2 \alpha+4}
$$

From these relationships it is evident that the ratio of volume to surface area is L/6 for short cylinders, spheres or cubes for any size. This ratio would become smaller for cylinders or sheets of larger aspect ratio (i.e. length/diameter or length/thickness). Time to process can be related directly to $\mathrm{L}$ when the oxygen consumption rate predictions are fit to a power law equation (see Table II).

$$
R_{O 2}^{i}=A L^{-B}
$$

where $\mathrm{A}$ and $\mathrm{B}$ are constants, A having units of $\mathrm{g} /\left(\mathrm{cm}^{(2-\mathrm{B})}\right.$ hour $)$

So it follows that the time to process can be expressed solely as a function of $\mathrm{L}$ for a given shape.

$$
\begin{array}{cl}
\text { Sphere, Cylinder }(\mathrm{L} / \mathrm{D}=1) \text { or Cube: } & t_{f}=\frac{15.2}{84.8} \rho_{U} \frac{L}{6 * A L^{-B}} \\
\text { Sheet }(\mathrm{L}=\text { length and width, thickness }=\mathrm{L} / \alpha) & t_{f}=\frac{15.2}{84.8} \rho_{U} \frac{L}{(2 \alpha-4)^{*} A L^{-B}}
\end{array}
$$

Based on these relationships, the time to process can be calculated for different geometries. In Figure 11 , the mass of the object and the time to process completion are plotted with respect to the characteristic dimension. For example, a $10 \mathrm{~cm}$ diameter sphere of uranium weighs $\sim 9950$ grams and takes just over 5 hours to completely oxidize, if the sample burns at the maximum rate. If the sample's surface area is increased and forced convection is implemented the effective process time will be shorter.

Using the ash-layer diffusion model, developed by Laurinat, ${ }^{11}$ it is more difficult to estimate the time to process because the burning rate is determined by diffusion across a growing oxide layer. Based on the assumptions in reference 11, the process times would be longer than those times predicted for the previous model developed by Mouradian and Baker ${ }^{4}$. In reality, the time to process would likely be between the two models, since the assumptions in both models bound the actual case. 


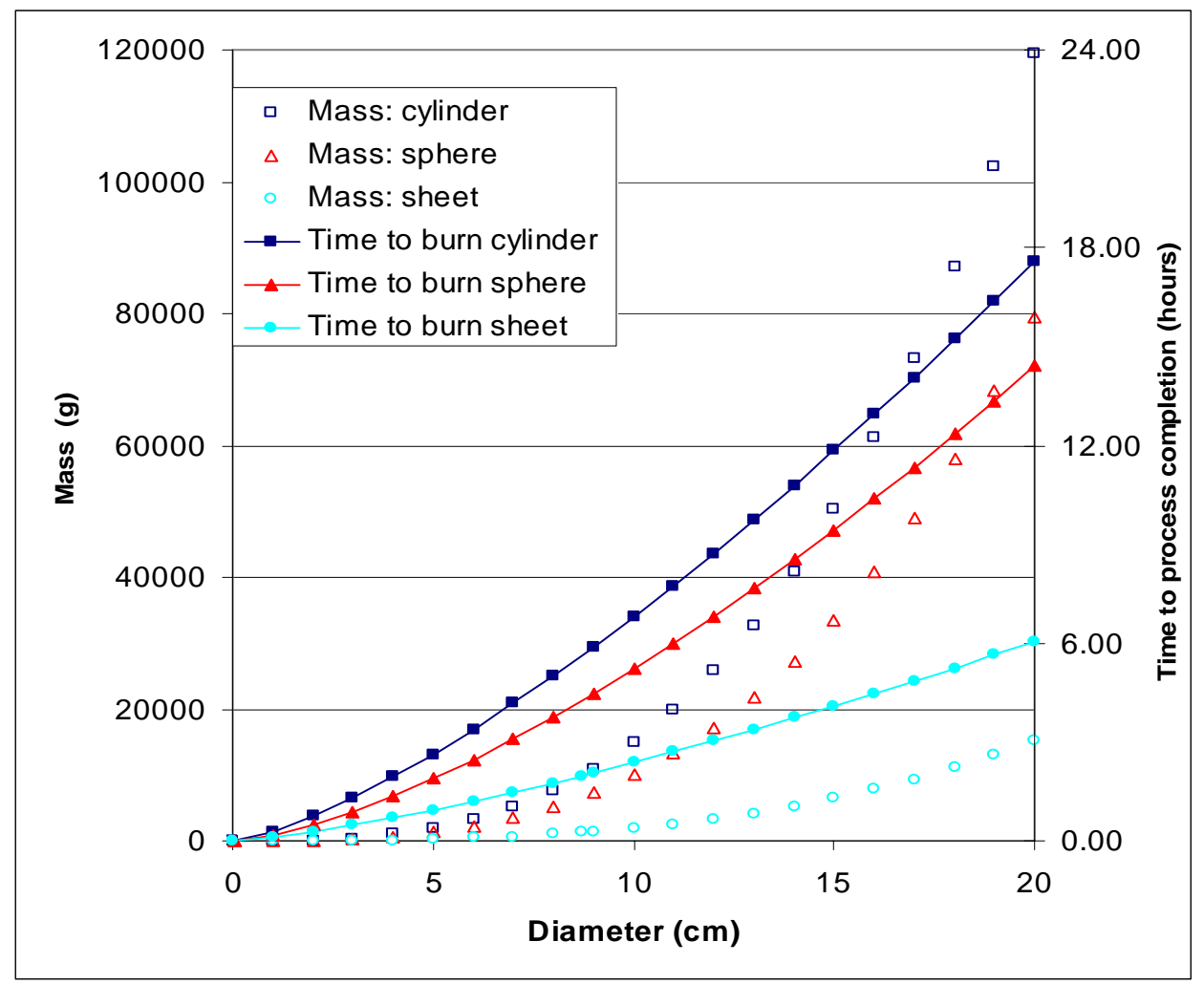

Figure 11: Time to complete oxidation as a function diameter for Uranium metal cylinder, sphere and vertical plate (length/thickness $=1 / 5$ ) in natural convection using rate(s) from Table II.

\subsection{Oxide Characteristics}

The characteristics of the oxide product depend largely on the temperature at which the metal is oxidized. In the case of higher through-put, high temperature reactions, the oxide is denser and not as easily oxidized in a dissolver system. Conversely, by running at lower temperatures where it takes longer to completely oxidize the material, the oxide produced is much less dense and is oxidized much more quickly. This quick oxidation can lead to difficulties when large batches are fed to dissolver systems. Consequently, the oxide production conditions must be optimized to balance throughput and product oxidation properties depending on the end use of the material. Process conditions used to produce high and low temperature oxides, as well as, the properties of these oxides for use in dissolver systems could be investigated using pilot scale testing. 


\subsection{SUMMARY AND RECOMMENDATIONS}

Based on literature and available data, key parameters have been evaluated which affect the oxidation of uranium metal in air. The findings summarized in this report address these following area:

- The oxidation rate that can be expected for massive uranium (>1 kg) in a diffusion controlled environment can vary between 60 and $1000 \mathrm{mg} \mathrm{O} / \mathrm{cm}^{2} / \mathrm{hr}$ above $500{ }^{\circ} \mathrm{C}$.

- Cycle times will vary based on surface area per mass of shape, air flow, rate and temperature.

- While the use of high flow forced-air does significantly enhance the oxidation rate, this variable will again depend on the shape mass and furnace temperature. A furnace configuration where the mass is sitting on a grate and the oxide is collected in a trap after air filtration would facilitate easy removal of the oxide powder. Process conditions for such an arrangement should be investigated and optimized to maximize throughput.

- The furnace temperature above $600{ }^{\circ} \mathrm{C}$ is recommended, in order to start the oxidation process. After initiation, the set point of the furnace should be adjusted in order maintain the target oxidizing temperature. This target temperature will be determined by the desired oxidation rate. A pilot scale process to optimize the temperature and air flow rates could be performed.

- Contamination controls should be implemented to control the oxide particles that are in the air flow. A method to monitor both slug temperature as well as the progress of the oxidation should be determined. Process monitoring and furnace/forced-air systems should be integrated to adapt in real-time to the oxidation of the material. Filtration or conditioning of off-gas or waste streams is needed to remove heat and any oxide to the degree expected in typical HEPA systems for radiological (uranium) applications.

- For a uranium oxidizer, the equipment features that are likely to be of primary importance would be those that assist in the uniform flow of air through the sample chamber, the isolation of oxide particles from components downstream from the process and collection of the oxide. A properly designed furnace retort (reaction chamber) with mass flow controls would ensure proper gas flow conditions, as well as minimize the spread on contamination to the furnace components. Cyclone separation of exhaust gases would aid in the collection of oxides and could prevent the contamination of components down stream. The design of the furnace can be modified with slight mechanical vibration to more effectively expose fresh metal surface as the oxide spalls off of the specimen. 


\section{References}

${ }^{1}$ Hilton, B. A., "Review of Oxidation Rates of DOE Spent Nuclear Fuel, Part I Metallic Fuel,” ANL 00/24, Argonne National Laboratory, November, 2000.

${ }^{2}$ Bagley, K. Q. and Oliver, D. S., "The Oxidation of Uranium in Air,” R \&DB (D) TN-32, United Kingdom Atomic Energy Authority, Risley, Warrington, Lancashire, UK, May, 1953.

${ }^{3}$ Isaacs, J. W. and Wanklyn, J. N., "The reaction of Uranium with Air at High Temperatures,” AERE-R 3559, Atomic Energy Research Group, United Kingdom, December 1960

${ }^{4}$ Mouradian, E. M. and Baker, L. Jr., Nuclear Science and Engineering, 15, 388-394 (1963)

${ }^{5}$ Schnizlein, J.G., et. al., "Ignition Behavior and Kinetics of Oxidation of the Reactor Metals, Uranium, Zirconium, Plutonium, and Thorium, and Binary Alloys of Each”, Status Report, ANL-5974, Argonne National Laboratory, April, 1959.

${ }^{6}$ Baker, L. Jr. and Bingle, J. D., Journal of Nuclear Materials, 20, pp. 11-21, (1966).

${ }^{7}$ Baker, L. Jr., Schnizlein, J. G. and Bingle, J. D., Journal of Nuclear Materials, 20, pp. 22-38, (1966)

${ }^{8}$ Hilliard, R. K. “Oxidation of Uranium in Air at High Temperatures,” Report \# HW-58022, December 10, 1958.

${ }^{9}$ D. K. Veirs, et al. "Gas generation and Corrosion in salt containing impure Plutonium oxide materials: Initial Results for ARF-102-85-223” Document \# LA-UR-04-1788, Los Alamos National Laboratory, Los Alamos, NM (2004)

${ }^{10}$ Chemical Engineering Division Summary Report, Argonne National Laboratory, July, August, September, pp. 136-157 (1960)

${ }^{11}$ J. E. Laurinat, “Analysis of Burning Plutonium Alloy in FB-Line Furnaces,” Calculation No. X-CLC-F-00429, Savannah River Site, 9/25/03. 
T.M. Adams, SRNL

R.L. Bickford, SRNL

G.T.Chandler, SRNL

L. B. \{Penny\} Cunningham, Y-12

A.J. Duncan, SRNL

D.J. Hathcock, SRNL

N.C. Iyer, SRNL

R. S. Johnson, Y-12

D. K. Little, Y-12

L.W. Little, Process Engineering Associates

G. L. Pfennigwerth, Y-12

J. K. Prazniak, Y-12

R.L. Sindelar, SRNL

L. H. Stinton, Y-12

S.L. West, SRNL 